\title{
Sleep Quality among Nurses during the First Year of Coronavirus Disease 2019
}

\author{
Wafa Ibrahim Alharbi ${ }^{1}$, Amani Mahrus $^{2}$, Shadia Elsayed ${ }^{3,4 *} \mathbb{D}$, Albraa B. Alolayan $^{3}$ \\ ${ }^{1}$ Family Medicine Resident, National Guard Hospital Program, Almadinah Almunawwarah, Saudi Arabia; ${ }^{2}$ Department of Family \\ and Community Medicine, Prince Mohammed Ben Abdulaziz Hospital, Almadinah Almunawwarah, Saudi Arabia; ${ }^{3}$ Department \\ of Oral and Maxillofacial Surgery, Taibah University, Almadinah Almunawwarah, Saudi Arabia; ${ }^{4}$ Department of Oral and \\ Maxillofacial Surgery, Al-Azhar University, Cairo, Egypt
}

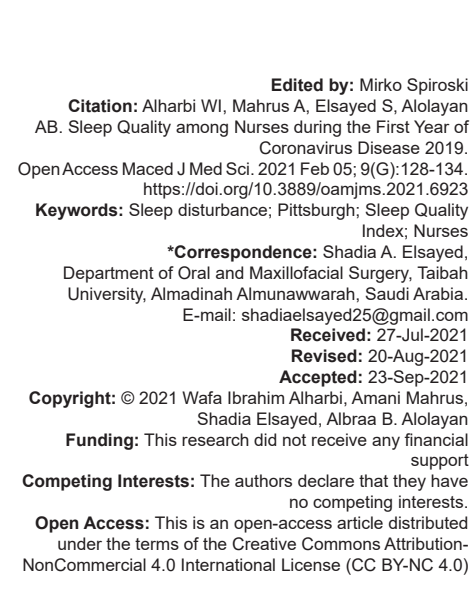

\section{Introduction}

The global pandemic coronavirus disease 2019 (COVID-19) is the most challenging condition humanity has encountered in the twenty-first century [1], [2]. This pandemic has an impact on every sector of our life, particularly due to a lack of knowledge about the virus's route of transmission and how to treat and prevent it [2], [3]. Every society was negatively affected by the pandemic's psycho-emotional consequences. Although a considerable portion of the population can demonstrate strength and courage in the face of stress, anxiety, or loss caused by the pandemic, the virus can damage the psychological health of a smaller portion of the population, increasing stressrelated problems [4].

Sleep is a physiological processing of body renewal [5]. It has two dimensions: Duration (quantity) and depth (quality) [6]. Sleep is one of basic Maslow's hierarchy needs for human beings [7]. Poor sleep quality has an impact on not only thinking abilities but also emotions, performance, and health [8].
Nurses represent the largest sector of healthcare professionals, so they have a significant role in the health-care system, which is adversely affected by poor sleep quality as it results in not only health problems, but also it is linked to weak employee performance and increase in the likelihood of making medical mistakes that endanger the patient's life [9].

The nurses' work is characterized by various day and night shifts and irregular activity [10]. Sleep disturbances in the form of irregular sleep-wake patterns have been reported in up to $57 \%$ of shift-working nurses, resulting in decreased sleep time and daily dysfunction [11].

National researchers in Taif, 2018 [12], looked into the relationship between sleep quality and medical students' grades. Researchers at King Abdulaziz University in Jeddah found that $70.4 \%$ of medical students had low sleep quality in 2017 [13] and found no important associations between them. In Najran, a 2017 [14] sleep quality analysis among health-care staff found that a majority of them were nurses, and $42.3 \%$ of the workers were bad sleepers.

Clinicians attempted to measure sleep quality and nurse productivity in Taiwan, 2013 [15], the UK, 
2017 [16], Nigeria, 2017 [17], and South Korea, 2018 [18], and all results revealed that sleep quality disturbance is a common problem among nurses.

In addition, the Saudi transformation plan for 2020 concentrates on human practice quality and scientific skills. Furthermore, the Saudi vision 2030 aims to increase the quality of employee performance by enhancing soft skills, which are one of the most significant parts of a qualitative human investment. As a result, nurses play an important part in the development of health care.

COVID-19 time effects on sleep quality and performance among nurses in Al-Madinah city, Saudi Arabia, have never been studied. As a result, the aim of the present study was to determine the prevalence of poor sleep quality among nurses in the National Guard Health Affairs in Al-Medina district, Saudi Arabia, in 2020 (the $1^{\text {st }}$ year of the COVID-19 crisis), and to assess any correlation between demographic characteristics and sleep quality.

\section{Materials and Methods}

\section{Study area}

The research was carried out in Saudi Arabia's Al-Madinah city's National Guard Health Affairs. Saudi Arabia is the Arab world's second-largest nation. Madinah is a city in Saudi Arabia's northwestern region. Medina covers an area of (589) square kilometers. It is about 150 miles north of Mecca and 400 miles south of the Red Sea.

Al-Madinah's Prince Mohammed Bin Abdulaziz Hospital (PMBAH), "the fifth National Guard Health Facility in the Kingdom," is a completely serviced facility with a 215-bed ability, located on Prince Naif Road at the foot of Mount Uhud. The National Guard employees and their dependents, as well as other deserving patients, are served by the Prince Mohammad Bin Abdulaziz Hospital. It covers three departments' inpatient, outpatient, and emergency. Nurses from various countries work in all departments.

\section{Study design and population}

Nurses from the National Guard Hospital and the primary health-care centers (PHCCs) in Al-Madinah city participated in a cross-sectional descriptive analysis.

\section{Inclusion criteria}

Nurses at the National Guard Hospital and the PHCC in Al-Madinah by 2020.

\section{Exclusion criteria}

- $\quad$ Administrative nurses working in the National Madinah's Guard Hospital in 2020

Nurses on leave at the National Guard Hospital, Al-Madinah, in 2020 during data collection.

\section{Sample size and sampling technique}

Raosoft's sample calculator was used to measure the represented study population size. The total number of nurses is 620 , with a margin error of 5 and 95 confidence level; a sample size of 238 was suggested. The hospital is divided into 12 departments, with 19 nurses randomly selected from each department due to the fact that all department shifts are scheduled at the same time. The study sample was conveniently expanded to include ten nurses from a primary healthcare center in the same study region.

\section{Study tool}

A previously validated questionnaire was used to collect data for the study. It is divided into two sections: The first contains sociodemographic information such as age, nationality, marital status, and gender. The Pittsburgh Sleep Quality Index (PSQI) was used in the second portion.

The PSQI is a useful tool for assessing the quality and patterns of adult sleep. Sleep quality disturbances, latency, length, habitual quality, use of drugs, and daytime dysfunction over the previous month are used to distinguish "poor" from "good" sleep quality.

\section{Data entry and analysis}

IBM SPSS version 24 was used to analyze the data in this report (IBM Corp., Armonk, N.Y., USA). The characteristics of the study variables were described using a simple descriptive statistic in the form of counts and percentages for categorical and nominal variables and mean and standard deviations for continuous variables. The key research variable was measured using the (PSQI) scoring system.

The Chi-square test was used in this analysis to create a relationship between demographics and the key study variable. Finally, the null hypothesis was refused if the $p<0.05$.

\section{Results}

In this study, the sleep quality of 238 nurses in the National Guard Health Affairs in Al-Medina city, 
Saudi Arabia, was evaluated. The demographic profile of the studied population showed that nearly $40 \%$ of the participants were found to fall between 31 and 35 years old $(37.8 \%)$, followed by around one-fourth whose aged 30 years old and below (24.4\%). Almost half of them $(46.6 \%)$ were Malaysian and roughly one-third $(34.0 \%)$ were of Filipino nationality. Majority of the studied nurses were female (84.0\%). About three-fourth of them were married at least once $(72.6 \%)$. Furthermore, most of them were non-smokers $(94.5 \%)$ and working in the hospital (96.2\%) (Table 1).

Table 1: Participants' demographic profile characteristics $(n=238)$

\begin{tabular}{lll}
\hline Demographics & Count & $\%$ \\
\hline Age & & \\
30 years old and below & 58 & 24.4 \\
$31-35$ years old & 90 & 37.8 \\
$36-40$ years old & 52 & 21.8 \\
Above 40 years old & 38 & 16.0 \\
Nationality & 11 & 4.6 \\
Saudi & 111 & 46.6 \\
Malaysian & 81 & 34.0 \\
Filipino & 3 & 1.3 \\
Sudanese & 18 & 7.6 \\
Jordanian & 10 & 4.2 \\
Egyptian & 2 & 0.8 \\
British & 1 & 0.4 \\
Australian & 1 & 0.4 \\
Pakistani & & \\
Gender & 38 & 16.0 \\
Male & 200 & 84.0 \\
Female & & 27.4 \\
Marital status & 65 & 72.6 \\
Single & 173 & 27.4 \\
Married at least once & & 69.3 \\
Marital status & 65 & 2.5 \\
Single & 165 & 0.8 \\
Married & 6 & 94.5 \\
Widowed & 2 & 5.5 \\
Separated & & \\
Smoking & 225 & \\
Non-smoker & 13 & \\
Smoker & & \\
\hline & &
\end{tabular}

Table 2 shows the sleep routine characteristics of the participants. Around 40\% (39.9\%) of them have usually gone to bed between 10:01 PM and 12:00 midnight, while nearly one-third between 8:00 PM and 10:00 PM (28.6\%). Furthermore, $50.8 \%$ of them took 30 min and less to fall asleep each night. $68.9 \%$ woke up in the morning between 4:01 AM and 6:00 AM, 61.8\% had an actual 6-8 h of sleep at night, and $57.4 \%$ stayed in bed for $6-8 \mathrm{~h}$.

Table 2: Sleeping pattern of the participants

\begin{tabular}{llll}
\hline Variables & & Count & $\%$ \\
\hline When do you normally go to & $20: 00-22: 00$ & 68 & 28.6 \\
bed? (24-h format) & $22: 01-00: 00$ & 95 & 39.9 \\
& Pass 00:00 & 29 & 12.1 \\
& After work/duty & 46 & 19.3 \\
How long does it take you to & 30 min and less & 121 & 50.8 \\
fall asleep each night & $31-60$ min & 65 & 27.4 \\
(in minutes)? & $61-120$ min & 29 & 12.2 \\
& More than 120 min & 16 & 6.7 \\
How early do you normally & Not sure & 7 & 2.9 \\
get up in the morning? & 02:00-04:00 & 40 & 16.8 \\
& 04:01-06:00 & 164 & 68.9 \\
How many hours did you & Pass 06:00 & 22 & 9.3 \\
get off real sleep at night? & Before work/duty & 12 & 5.0 \\
& $5 \mathrm{~h}$ or less & 79 & 33.2 \\
How many hours were you & $6-8 \mathrm{~h}$ & 147 & 61.8 \\
in bed? & More than $8 \mathrm{~h}$ & 11 & 4.6 \\
& Not sure & 2 & 0.4 \\
& $5 \mathrm{~h}$ or less & 53 & 23.0 \\
& $6-8 \mathrm{~h}$ & 132 & 57.4 \\
& More than $8 \mathrm{~h}$ & 34 & 14.8 \\
\hline
\end{tabular}

In terms of sleep-related trouble encounters, around $40 \%$ and one-fourth of the studied population were unable to fall asleep in $<30$ min three or more times a week $(39.6 \%)$ and once or twice a week $(26.0 \%)$. On the other hand, nearly half of them reported waking up in the middle of the night or early in the morning three or more times a week $(48.1 \%)$. About one-third of the nurses surveyed $(32.6 \%)$ had to get up to use the bathroom once or twice a week, and three or more times a week (33.9\%). Furthermore, almost half of them reported feeling overheated $(48.9 \%)$, had bad dreams $(49.6 \%)$ cannot breathe comfortably $(74.8 \%)$, coughed or snore loudly $(72.6 \%)$, felt too cold $(56.4 \%)$, experienced pain $(53.8 \%)$, and other reasons $(48.9 \%)$ not during the past month. Other reasons include too much thinking $(15 \%)$, post night shift $(20 \%)$, and pain and sickness $(22.5 \%)$ at more than $15 \%$ rate.

The recent month-related experiences of the participants were also determined. The majority of them $(75.5 \%)$ have taken medication to help them fall asleep, and $60.9 \%$ have had difficulty staying awake while driving, eating, or engaging in social activity in the previous month. Nearly half of the respondents, on the other hand, did not find it difficult to maintain their enthusiasm for getting things done over the past month (49.3\%). Almost half rated their sleep quality as good overall (49.8\%). After accounting for the causes of trouble in sleeping of the participants, the average quality sleep score of the participants was found to be $25.26 \pm 7.1(\min =5, \max =39)$.

From Table 3, it is shown that the most commonly reported sleep problems were sleep latency, sleep disturbance, overall subjective sleep quality, and duration of sleep. Overall poor sleep quality was reported among $65.6 \%$ of the nurses, based on PSQI results.

Table 3: Objective sleep measures of the subjects

\begin{tabular}{|c|c|c|c|c|c|}
\hline Scoring & $\begin{array}{l}\text { Sleep Quality } \\
\text { Index }\end{array}$ & Min & Max & Mean & SD \\
\hline Duration of sleep & & 0 & 3 & 1.11 & 1.0 \\
\hline Sleep disturbance & & 0 & 3 & 1.43 & 0.6 \\
\hline Sleep latency & & 0 & 3 & 1.86 & 1.0 \\
\hline Day dysfunction due to sleepiness & & 0 & 3 & 0.86 & 0.9 \\
\hline Sleep efficiency & & 0 & 3 & 0.34 & 0.8 \\
\hline Overall sleep quality & & 0 & 3 & 1.22 & 0.8 \\
\hline Need meds to sleep & & 0 & 3 & 0.38 & 0.8 \\
\hline \multirow[t]{2}{*}{ Pittsburgh sleep quality index } & & 0 & 18 & \multirow{2}{*}{\multicolumn{2}{|c|}{$\begin{array}{ll}6.98 & 3.4 \\
\% & \end{array}$}} \\
\hline & & Count & & & \\
\hline \multirow[t]{2}{*}{ Pittsburgh sleep quality index } & Good sleep quality & 82 & & \multicolumn{2}{|c|}{34.4} \\
\hline & Poor sleep quality & 156 & & \multicolumn{2}{|c|}{65.6} \\
\hline
\end{tabular}

The correlation of the quality of sleep score of the studied nurses toward demographic factors was also investigated, as shown in Table 4. Results revealed no significant differences $(p>0.05)$ in their quality sleep score when compared against factors such as age, gender, family status, smoking characteristics, and place of work.

\section{Discussion}

COVID-19 crisis revealed the importance of the nursing profession in these circumstances. As a 
Table 4: Association between demographic characteristics of the participants and overall sleep quality

\begin{tabular}{llll}
\hline Demographics & \multicolumn{2}{l}{ Pittsburgh Sleep Quality Index } & p-value \\
\cline { 2 - 3 } & Good sleep quality & Poor sleep quality & \\
\hline Age & & & \\
30 years old and below & $(30.6)$ & $(69.4)$ & 0.899 \\
31-35 years old & $(37.3)$ & $(62.7)$ & \\
36-40 years old & $(34.3)$ & $(65.7)$ & \\
$\quad$ Above 40 years old & $(31.0)$ & $(69.0)$ & 0.097 \\
Gender & & $(50.0)$ & \\
$\quad$ Male & $(50.0)$ & $(68.1)$ & \\
$\quad$ Female & $(31.9)$ & $(72.5)$ & \\
Marital status & & $(63.3)$ & 0.290 \\
$\quad$ Single & $(27.5)$ & $(65.8)$ & \\
$\quad$ Married at least once & $(36.7)$ & $(57.1)$ & \\
Smoking & & & \\
$\quad$ Non-smoker & $(34.2)$ & $(42.9)$ & \\
$\quad$ Smoker & &
\end{tabular}

result of the shortage of the nursing staff, health-care settings allow nurses to work longer shifts and many shifts per week, which result in sleep deprivation, which has been reported to affect adversely the nurses' performance and cause errors and accidents during work [19]. The current study has been carried out to assess the sleep quality among nurses in the National Guard Health Affairs in Al-Medina city, Saudi Arabia, during 2020 (the $1^{\text {st }}$ year of COVID-19 pandemic) and set recommendations to reduce the burden of the problem among the nurses.

Malik et al., 2018 [20], and many other researchers in Saudi Arabia used and assessed the construct validity of the PSQI index among different health-care workers in Jeddah, Riyadh, and Jazan and showed satisfactory results and similar findings as other developed countries who validate the PSQI index in many clinical and subclinical settings [21], [22].

In the current study, the mean PSQI score was $6.98 \pm 3.9$, which is lower than that reported in Shandong, China, among nurses working in the emergency department in public hospitals (8.2 \pm 3.9 ), secondary hospitals $(9.5 \pm 3.9)$, and tertiary hospitals $(11.8 \pm 4.3)$. However, it was comparable to that reported in primary hospital $(7.4 \pm 3.5)$ [23]. Furthermore, the current study revealed an overall prevalence of bad quality of sleep (PSQI $>5$ ) of $65.6 \%$ compared to $76.3 \%$ and $63.9 \%$ among emergency nurses and registered nurses, respectively, in China [23], [24], 78.5\% among hospital staff nurses in Taiwan [15], and 57\% among nurses in another study carried out in Taiwan [11]. In Nigeria, $61 \%$ of the nurses had poor sleep quality and the mean PSQI score was $5.7 \pm 2.7$ [17], and in another study, $58.3 \%$ of nurses had poor sleep quality [25]. In Newcastle (UK), the prevalence of poor sleep quality was $59 \%$ in none work-shifting nurses and $78 \%$ in work-shifting nurses [16]. In Tehran (Iran), poor quality of sleep was reported among $41 \%$ of health-care workers [26]. Finally, in another Saudi study carried out in Najran, $48.6 \%$ of nurses reported poor sleep quality [14].

According to Sher, 2020 [27], a comparison of the current study's findings with those of previous recent research released during the COVID era revealed that the pandemic is linked to increasing rates of anxiety, sleep difficulties, and even suicide [28], [29]. Others attributed the pandemic's impact on immune systems to the pandemic. Others have linked the pandemic's influence on immune systems not only for medical personnel and nurses but also for the general public [30].

In the present study, $50.8 \%$ of the nurses fell into sleep within 30 min or less whereas $27.4 \%$ took between 31 and 60 min and overall sleep latency was the most commonly reported sleep problem among them. In Nigeria, the average time taken by nurses to fall into sleep was $21.7 \pm 15.8$ min [17]. Furthermore, in Iran, sleep latency was the most important problem of the nurses [31].

In the current survey, the duration of sleep range between 6 and $8 \mathrm{~h}$ among $61.8 \%$ of the nurses while $33.2 \%$ sleep $5 \mathrm{~h}$ or less. In Nigeria, the duration of sleep ranged between 1 and $10 \mathrm{~h}$, with a mean of $6.2 \pm 1.5$ [17]. It has been recently documented that shorter sleep duration has a negative impact on the nursing work performance [32].

The present study revealed no significant difference in the rate of poor sleep quality between nurses working in hospitals and those working in primary health-care settings. The inclusion of a very small sample size from primary healthcare centers compared to those recruited from hospitals is most likely the reason for this result. In a similar study carried out in China, the prevalence of bad quality of sleep among emergency nurses was related significantly to the hospital level [23].

Numerous studies found an association between decreased quality of sleep and working in shifts as well as increase in the workload [15], [33], [34], [35], [36], [37]. In the present study, we classified our population into two categories: Those working in hospitals with a shift schedule and excessive workload and those working in primary health-care centers with only a morning shift and relatively low workload. We did not observe a significant difference between the two groups as regards the prevalence of poor sleep quality. Some other studies did not reveal an association between work shifts and quality of sleep [38]. Other studies suggested that hospital nurses were highly stressed and more prone to sleep problems [39], [40].

In the present study, almost one-quarter of nurses $(24.5 \%)$ reported taking medications to help them to sleep in the past month. High figure has been reported by Bagheri et al. in Iran (35.5\%) [38]. In another study carried out by Sepehrmanesh et al. also in Iran [41], 19.5\% of nurses used sleep medication to fall asleep. In the United States, $27 \%$ of nurses used medications to help them sleep, while $13 \%$ reported using medications to stay awake [42]. Sleep 
medications have adverse impacts on the quality of life because they may lead to some unpleasant symptoms including headache, dizziness, concentration problems, vomiting, sleepiness, insomnia and also it could affect memory [43], [44], [45], [46].

It has been documented in the literature that the factors that had considered as risk factors for bad sleep among nurses collectively include shift work, personal lifestyle and characteristics, work-related characteristics, family structure, and chronic symptoms such as headaches, abdominal pain, head and back pain, and fatigue [47]. In the present study, we investigated only demographic characteristics of nurses in addition to place of work (hospital versus primary health-care center) and found no association with poor sleep quality. Similar to ours, some other studies found no association between demographic characteristics of nurses and poor sleep quality [15], [48]. Contrary to that, Chan [49] observed that older age, gastrointestinal symptoms, and higher level of stress were determinants of poor sleep among nurses. Kageyama et al. reported that nurses under the age of 27 who worked three night shifts a month were more likely than others to have sleep problems [50].

The current research has some limitations. It was only performed at one hospital, restricting the applicability of the results to other settings. The cross-sectional design of the study and collection of data by a self-report tool and none using objective tests were considered limitations of the study. Despite those limitations, this study has public health importance in exploring the problem of sleeping disturbance among nurses during pandemic times that could impact the quality of care delivered to patients in our community.

\section{Conclusions}

Sleep problems during the $1^{\text {st }}$ year of COVID19 crisis are very common among nurses working at the National Guard Health Affairs and primary health-care centers in Al-Medina city, Saudi Arabia, as it affected almost two-thirds of them, with no difference based on their demographic characteristics. Sleep latency, sleep disturbance, subjective overall sleep quality, and sleeping time were the most commonly observed sleep problems among nurses.

\section{Recommendations}

During pandemics such as COVID-19, adjunctive interventions are required to increase sleep efficiency among nursing personnel, specifically the frequency and duration of night shifts.

\section{Ethical Considerations}

This study was conducted according to the principles of the World Medical Declaration of Helsinki and approved by the King Abdullah International Medical Research Center (IRBC/1076/20). Each nurse had to sign a written consent form. The privacy and confidentiality of participants were protected; no identifiers were obtained and all data, hard and soft copies, were maintained on the hospital premises and only the research team had access to it.

\section{Authors' Contributions}

WA was in charge of the study's conception and design, as well as conducting analysis, providing research materials, and collecting and organizing data. Data were analyzed and interpreted by AM and SAE. WA and ABA contributed to the initial and final revisions of the paper, as well as material support. The manuscript's content and similarity index are the responsibility of all authors, who have critically revised and accepted the final document.

\section{References}

1. Elsayed SA, Abu-Hammad O, Alolayan AB, Eldeen YS, DarOdeh N. Fallacies and facts around COVID-19: The multifaceted infection. J Craniofac Surg. 2020;31(6):e643-4. http://doi. org/10.1097/SCS.0000000000006752

PMid:32649559

2. Elsayed SA, Abu-Hammad $O$, Alolayan AB, Althagafi $N$, Ayed $Y$ Eldeen YS, et al. Getting to know SARS-CoV-2: Towards a better understanding of the factors influencing transmission. Pesqui Bras Odontopediatr Clin Integr. 2020;20:1-7. https://doi. org/10.1590/pboci.2020.123.

3. Dar-Odeh $\mathrm{N}$, Elsayed S, Babkair H, Abu-Hammad $\mathrm{S}$ Althagafi N, Bahabri R, et al. What the dental practitioner needs to know about pharmaco-therapeutic modalities of COVID-19 treatment: A review. J Dent Sci. 2020;16(3):806-16. https://doi. org/10.1016/j.jds.2020.11.007

PMid:33230404

4. Horesh D, Brown AD. Traumatic stress in the age of COVID-19: A call to close critical gaps and adapt to new realities. Psychol Trauma. 2020;12(4):331-5. https://doi.org/10.1037/tra0000592 PMid:32271070

5. Wondie T, Molla A, Mulat H, Damene W, Bekele M, Madoro D, et al. Magnitude and correlates of sleep quality among undergraduate medical students in Ethiopia: Cross sectional study. Sleep Sci Pract. 2021;5:7. https://doi.org/10.1186/ s41606-021-00058-2

6. Cho H, Pavek K, Steege L. Workplace verbal abuse, nursereported quality of care and patient safety outcomes among 
early-career hospital nurses. J Nurs Manag. 2020;28(6):1250-8. https://doi.org/10.1111/jonm.13071

PMid:32564407

7. McLeod S. Maslow's Hierarchy of Needs Simply Psychology; 2007. Available from: http://www.simplypsychology.org/maslow. html

8. Edwards J. The Importance of Quality Sleep how it Affects Your Health. Volunteer Protection Programs Particip Associate Inc,; 2019. Available from: https://www.vpppa.org/blog-entry/ the-importance-of-quality-sleep-how-it-affects-your-health

9. Gaba DM, Howard SK. Fatigue among clinicians and the safety of patients. N Engl J Med. 2002;347(16):1249-55. https://doi. org/10.1056/NEJMsa020846 PMid: 12393823

10. Rogers AE. The effects of fatigue and sleepiness on nurse performance and patient safety. In: Patient Safety and Quality: An Evidence-Based Handbook for Nurses. Rockville, MD: Agency for Healthcare Research and Quality US; 2008. p. 1-38.

11. Shao MF, Chou YC, Yeh MY, Tzeng WC. Sleep quality and quality of life in female shift-working nurses. J Adv Nurs. 2010;66(7):1565- 72. https://doi. org/10.1111/j.1365-2648.2010.05300.x PMid:20492021

12. Alqarni $A B$, Alzahrani NJ, Alsofyani MA. The interaction between sleep quality and academic performance among the medical students in Taif university. Egypt J Hosp Med. 2018;70:2202-8. https://doi.org/10.12816/0045053

13. Ibrahim NK, Badawi FA, Mansouri YM, Ainousa AM, Jambi SK, et al. Sleep quality among medical students at king Abdulaziz university: A cross-sectional study. J Community Med Health Educ. 2017;7:561. https://doi.org/10.4172/2161-0711.1000561

14. Olawale O, Taiwo O, Hesham A. Quality of sleep and well-being of health workers in Najran, Saudi Arabia. Indian J Psychiatry. 2017;59(3):347-51. IndianJPsychiatry_241_16

PMid:29085095

15. Chien PL, Su HF, Hsieh PC, Siao RY, Ling PY, Jou HJ. Sleep quality among female hospital staff nurses. Sleep Disord. 2013;2013:283490. https://doi.org/10.1155/2013/283490

16. McDowall K, Murphy E, Anderson K. The impact of shift work on sleep quality among nurses. Occup Med (Lond). 2017;67(8):621- 5. https://doi.org/10.1093/occmed/kqx152 PMid:29040745

17. Aliyu I, Ibrahim ZF, Teslim LO, Okhiwu H, Peter ID, Michael GC. Sleep quality among nurses in a tertiary hospital in North-West Nigeria. Niger Postgrad Med J. 2017;24(3):168-73. https://doi. org/10.4103/npmj.npmj_79_17 PMid:29082906

18. Park E, Lee HY, Park CS. Association between sleep quality and nurse productivity among Korean clinical nurses. J Nurs Manag. 2018;26(8):1051-8. https://doi.org/10.1111/jonm.12634 PMid:29855101

19. Surani S, Murphy J, Shah A. Sleepy nurses: Are we willing to accept the challenge today? Nurs Adm Q. 2007;31(2):146-51. https://doi.org/10.1097/01.NAQ.0000264863.94958.40 PMid: 17413508

20. Malik AA, Bakarman MA, Butt NS. Construct validity and factor structure of the Pittsburgh Sleep Quality Index (PSQI) among physicians in Jeddah, Kingdom of Saudi Arabia. Pakistan J Stat Oper Res. 2018;14:935-43. https://doi.org/10.18187/pjsor. v14i4.2729

21. Mahfouz MS, Ali SA, Bahari AY, Ajeebi RE, Sabei HJ, Somaily SY, et al. Association between sleep quality and physical activity in Saudi Arabian university students. Nat Sci Sleep. 2020;12:775- 82. https://doi.org/10.2147/NSS.S267996
PMid:33117013

22. AISaif HI. Prevalence of and risk factors for poor sleep quality among residents in training in KSA. J Taibah Univ Med Sci. 2019;14(1):52-9. https://doi.org/10.1016/j.jtumed.2018.11.007 PMid:31435390

23. Dong $H$, Zhang $Q$, Zhu C, Lv Q. Sleep quality of nurses in the emergency department of public hospitals in China and its influencing factors: A cross-sectional study. Health Qual Life Outcomes. 2020;18:1-9. https://doi.org/10.1186/ s12955-020-01374-4

24. Dong $H$, Zhang $Q$, Sun Z, Sang F, Xu Y. Sleep disturbances among Chinese clinical nurses in general hospitals and its influencing factors. BMC Psychiatry. 2017;17(1):241. https://doi. org/10.1186/s12888-017-1402-3

PMid:28673267

25. Kolo E, Ahmed A, Hamisu A, Ajiya A, Akhiwu B. Sleep health of healthcare workers in Kano, Nigeria. Niger J Clin Pract. 2017;20(4):479-83. https://doi.org/10.4103/1119-3077.204378 PMid:28406131

26. Ghalichi L, Pournik O, Ghaffari M, Vingard E. Sleep quality among health care workers. Arch Iran Med. 2013;16(2):100-3. PMid:23360632

27. Sher L. COVID-19, anxiety, sleep disturbances and suicide. Sleep Med. 2020;70:124. https://doi.org/10.1016/j.sleep.2020.04.019 PMid:32408252

28. de Silva ES, Ono BH, Souza JC. Sleep and immunity in times of COVID-19. Rev Assoc Med Bras. 2020;66(Suppl 2):143-7. https://doi.org/10.1590/1806-9282.66.S2.143 PMid:32965373

29. Deng J, Zhou F, Hou W, Silver Z, Wong CY, Chang O, et al The prevalence of depression, anxiety, and sleep disturbances in COVID-19 patients: A meta-analysis. Ann N Y Acad Sci. 2021;1486(1):90-111. https://doi.org/10.1111/nyas. 14506 PMid:33009668

30. Marelli S, Castelnuovo A, Somma A, Castronovo V, Mombelli S, Bottoni D, et al. Impact of COVID-19 lockdown on sleep quality in university students and administration staff. J Neurol. 2021;268(1):8-15. https://doi.org/10.1007/s00415-020-10056-6 PMid:32654065

31. Salehi K, Alhani F, Sadegh-Niat K, Mahmoudifar Y, Rouhi N. Quality of sleep and related factors among imam khomeini hospital staff nurses. IJN. 2010;23:18-25.

32. Stimpfel AW, Fatehi F, Kovner C. Nurses' sleep, work hours, and patient care quality, and safety. Sleep Health. 2020;6(3):314-20. https://doi.org/10.1016/j.sleh.2019.11.001

PMid:31838021

33. Buysse DJ, Reynolds CF, Monk TH, Berman SR, Kupfer DJ. PSQI article.pdf. Psychiatry Res. 1998;28(2):193-213.

PMid:2748771

34. De Martino MM, Abreu AC, dos Barbosa MF, Teixeira JE. The relationship between shift work and sleep patterns in nurses. Cien Saude Colet 2013;18(3):763-8. https://doi.org/10.1590/ s1413-81232013000300022 PMid:23546203

35. Flo E, Pallesen S, Magerøy N, Moen BE, Grønli J, Nordhus IH, et al. Shift work disorder in nurses--assessment, prevalence and related health problems. PLoS One. 2012;7(4):e33981. https://doi.org/10.1371/journal.pone.0033981 PMid:22485153

36. Lin PC, Chen $\mathrm{CH}$, Pan SM, Pan CH, Chen CJ, Chen YM, et al Atypical work schedules are associated with poor sleep quality and mental health in Taiwan female nurses. Int Arch Occup Environ Health. 2012;85(8):877-84. https://doi.org/10.1007/ s00420-011-0730-8 
PMid:22207296

37. Roodbandi AS, Feyzi V, Khanjani N, Moghadam SR, Bafghi MS Moghadasi M, et al. Sleep quality and sleepiness: A comparison between nurses with and without shift work, and university employees. Int J Occup Hyg. 2017;8:8.

38. Sveinsdóttir H. Self-assessed quality of sleep, occupational health, working environment, illness experience and job satisfaction of female nurses working different combination of shifts. Scand J Caring Sci. 2006;20(2):229-37. https://doi. org/10.1111/j.1471-6712.2006.00402.x

PMid:16756530

39. Bagheri $H$, Shahabi $Z$, Ebrahimi H, Alaeenejad F. The association between quality of sleep and health-related quality of life in nurses. Tums Hayat. 2007;12:13-20.

40. Najimi A, Goudarzi AM, Sharifirad G. Causes of job stress in nurses: A cross-sectional study. Iran J Nurs Midwifery Res. 2012;17(4):301-5.

PMid:23833631

41. Sepehrmanesh Z, Mousavi G, Saberi H, Saei R. Sleep quality and related factors among the nurses of the hospital of Kashan university of medical sciences, Iran YR 2017/1/1. Int Arch Heal Sci. 2017;4:17-21. https://doi.org/10.4103/iahs. iahs_8_17

42. Christian FG, Muppavarapu K, Aston C, Bauer C, Doshi V. 0630 sleep health of nursing staff in an academic medical center: Results of a survey study. Sleep. 2019;42:A251-1.

43. Fitzgerald T, Vietri J. Residual effects of sleep medications are commonly reported and associated with impaired patient-reported outcomes among insomnia patients in the United States. Sleep Disord. 2015;2015:607148. https://doi. org/10.1155/2015/607148

PMid:26783470

44. Gómez-García T, Ruzafa-Martínez M, Fuentelsaz-Gallego C,
Madrid JA, Rol MA, Martínez-Madrid MJ, et al. Nurses' sleep quality, work environment and quality of care in the Spanish National Health System: observational study among different shifts. BMJ Open. 2016;6:e012073. https://doi.org/10.1136/ bmjopen-2016-012073

45. Poceta JS. Zolpidem ingestion, automatisms, and sleep driving: A clinical and legal case series. J Clin Sleep Med. 2011;7(6):632- 8. https://doi.org/10.5664/jcsm.1468

PMid:22171202

46. Roth AJ, McCall WV, Liguori A. Cognitive, psychomotor and polysomnographic effects of trazodone in primary insomniacs. J Sleep Res. 2011;20(4):552-8. https://doi. org/10.1111/j.1365-2869.2011.00928.x

PMid:21623982

47. Korompeli A, Chara T, Chrysoula L, Sourtzi P. Sleep disturbance in nursing personnel working shifts. Nurs Forum. 2013;48(1):45- 53. https://doi.org/10.1111/nuf.12005 PMid:23379395

48. Zhang L, Sun DM, Li CB, Tao MF. Influencing factors for sleep quality among shift-working nurses: A cross-sectional study in china using 3-factor Pittsburgh sleep quality index. Asian Nurs Res (Korean Soc Nurs Sci). 2016;10(4):277-82. https://doi. org/10.1016/j.anr.2016.09.002 PMid:28057314

49. Chan MF. Factors associated with perceived sleep quality of nurses working on rotating shifts. J Clin Nurs. 2009;18(2):285-93. https://doi.org/10.1111/j.1365-2702.2008.02583.x

PMid: 19120755

50. Kageyama T, Nishikido N, Kobayashi T, Oga J, Kawashima M. Cross-sectional survey on risk factors for insomnia in Japanese female hospital nurses working rapidly rotating shift systems. J Hum Ergol (Tokyo). 2001;30(1-2):149-54.

PMid:14564874 